\title{
The state dynamics of Scots pine communities under conditions of a decrease in airborne industrial pollution
}

\author{
Alexander Evdokimov ${ }^{1 *}$ \\ ${ }^{1}$ Herzen State Pedagogical University of Russia, 19118648 Moika River Emb., Saint Petersburg \\ Russia
}

\begin{abstract}
This work examines the changes in the life state of Scots pine communities located in the immediate vicinity of the source of aerial anthropogenic emission with a clear decrease in its level in the time interval 2015-2018. It is shown that due to the physiological and ontogenetic characteristics of woody forms of plants, the response to changes in the level of pollution by the tree layer will be insignificant in a relatively narrow time interval (within the limit of statistical error). However, this response to the reduction of pollution will still manifest itself. Also, one of the reasons for such a slow response can be considered the accumulation of heavy metals in the organic horizons of the soil, where heavy metals form complex compounds (chylates) that are inactive for eluvial processes. The most probable way of development of these communities, while maintaining the current level of emission, will be a gradual increase in the life state of the tree layer to a certain value.
\end{abstract}

\section{Introduction}

This paper presents a modern assessment of the components of boreal forests located in the immediate vicinity of one of the largest non-ferrous metallurgy plants in the Russian Federation and the largest plant in Europe - the Severonikel plant (Monchegorsk, Murmansk region). The main pollutants are polymetallic dust containing such elements as $\mathrm{Cu}, \mathrm{Ni}$ and $\mathrm{Co}$ (which are by-products of processing and smelting of non-ferrous ores) and sulfur dioxide - SO2 (which is formed during the primary processing of ores, the so-called "roasting"). The first sample plots in the region were established in the early 1970s. And in the future, employees of the Laboratory of Ecology of Plant Communities of the Botanical Institute named after V.L. Komanov RAS, constant monitoring of the ecological state of territories exposed to these pollutants is carried out [1]. Since the second half of the $90 \mathrm{~s}$ of the twentieth century, the plant has significantly reduced the amount of airborne emissions (Fig. 1, Fig. 2,), as evidenced by the data noted by some researchers at that time [2]. The cumulative nature of the accumulation (and release) of polymetallic dust has led to the fact that since the time when the ore processing plant decreased its activity, there has also been

\footnotetext{
* Corresponding author: evdokimov89@gmail.com
} 
a slight decrease in the content of heavy metals in the soil (Fig. 3) $[3,4,5,6]$. This paper presents materials obtained during field research in 2015 - 2018.

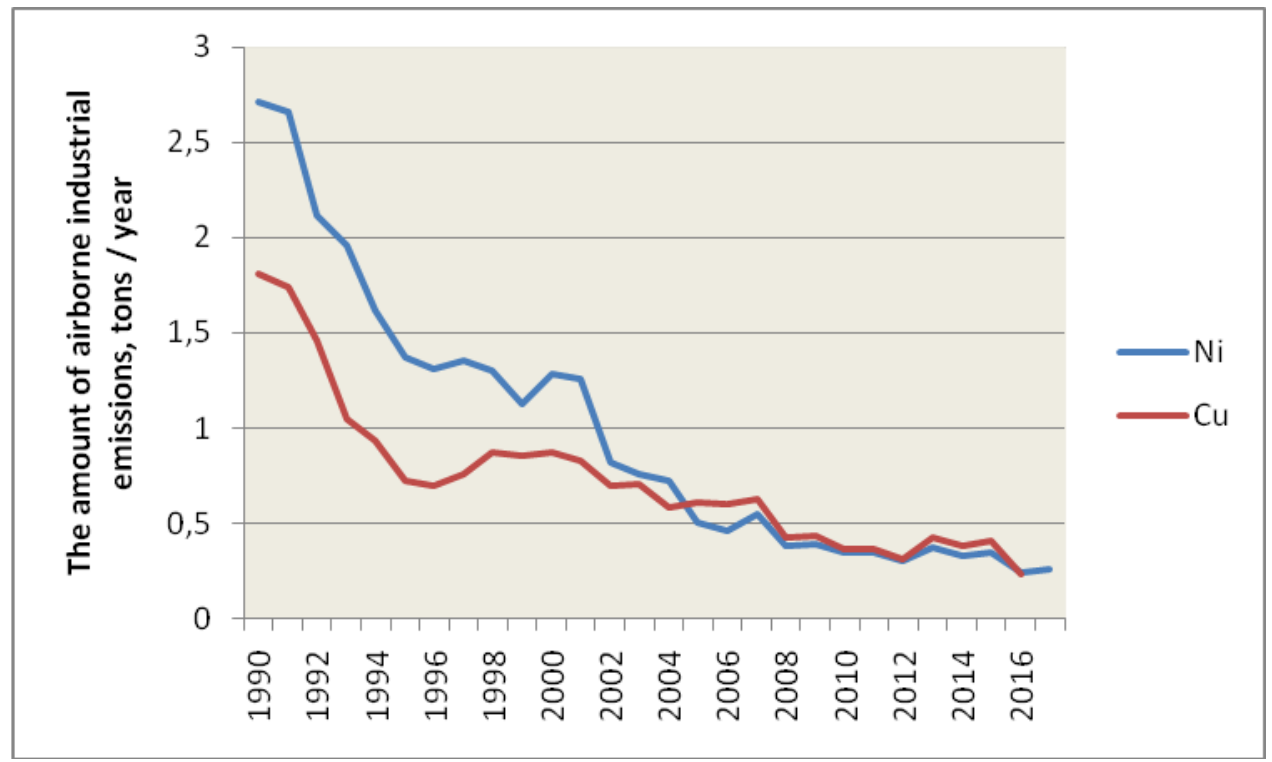

Fig. 1. Dynamics of atmospheric emissions of heavy metals from the Severonikel enterprise

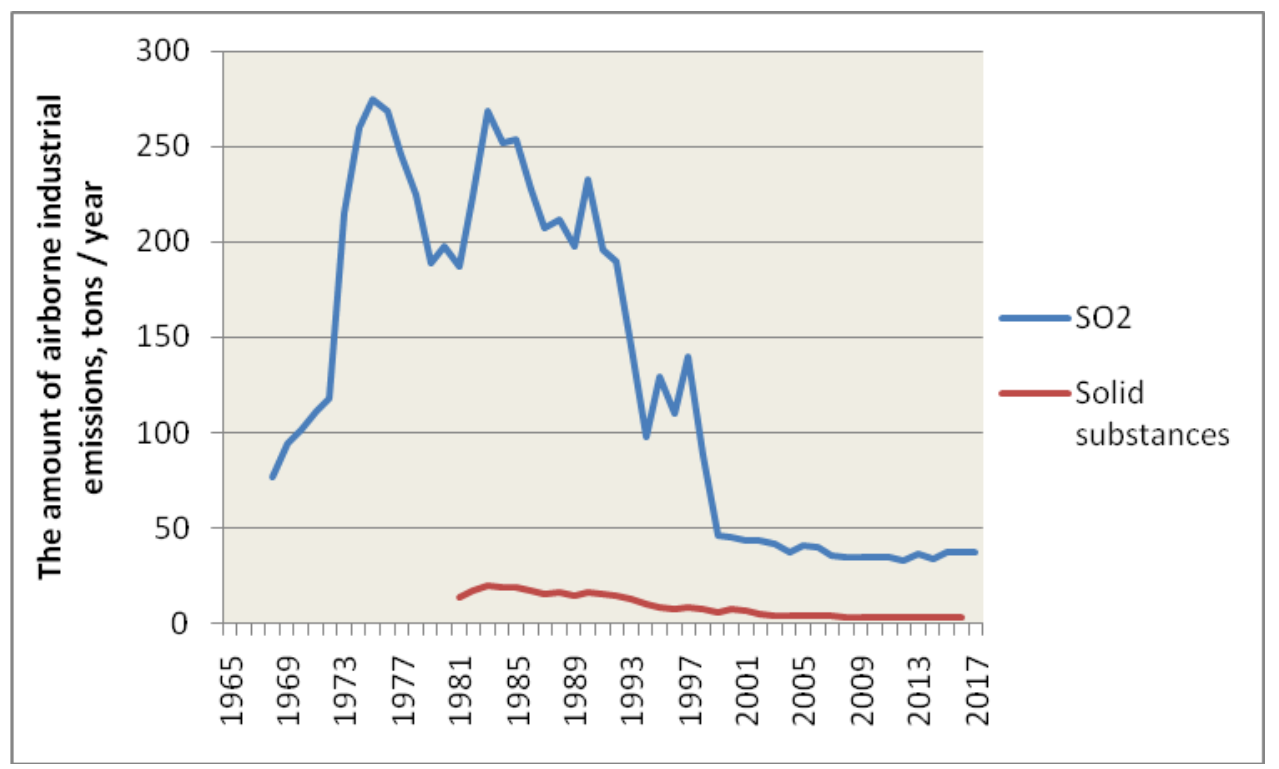

Fig. 2. Dynamics of atmospheric emissions of solid substances and sulfur dioxide from the Severonikel enterprise 


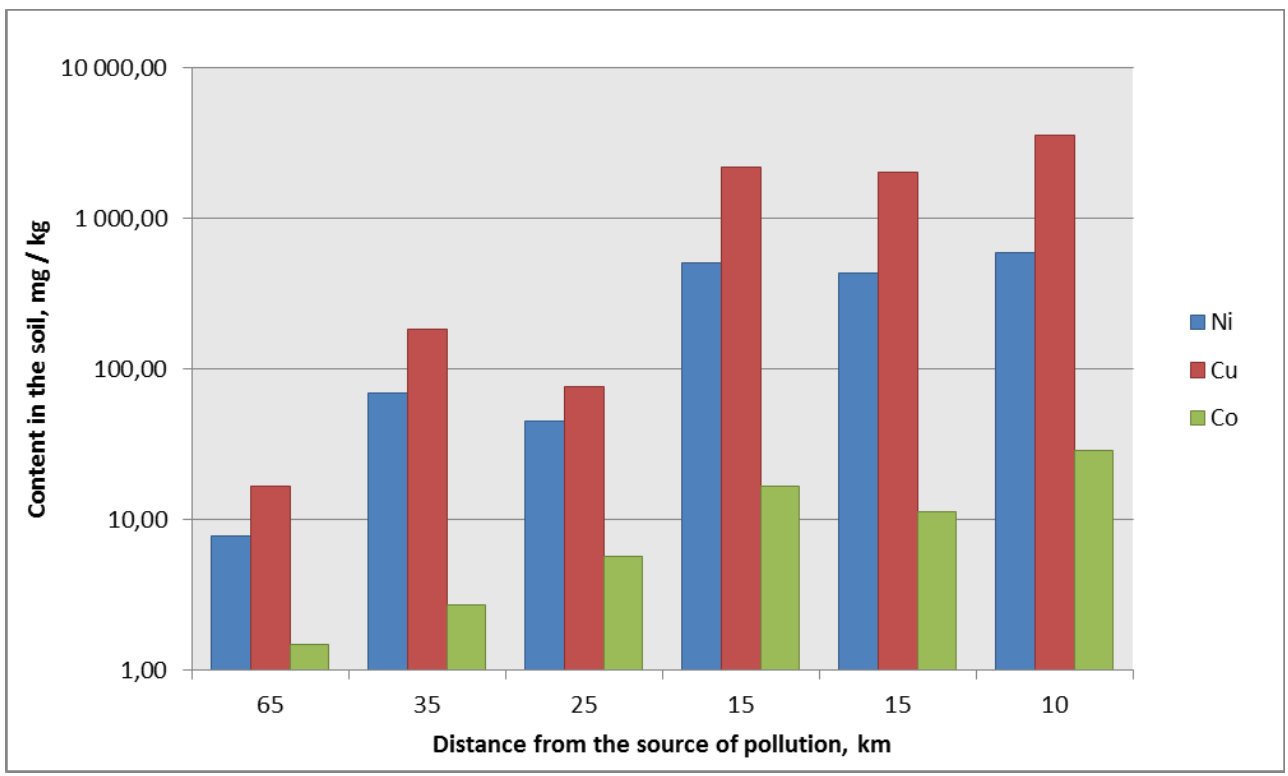

Fig. 2. The content of heavy metals in the organic soil horizon at different distances from the source of pollution (logarithmic scale of ordinates)

Scotch pine (Pinus sylvestris L.) is the main forest-forming species in the European taiga (along with other species - Siberian spruce (Picea obovata Ledeb) and European spruce (Picea abies (L.) H. Karst.)), Which makes it possible to use it as a model species in the study of the impact of various influences observed in a long time interval occurring in the taiga forests of the European North (including influences of an anthropogenic nature). It should also be noted that the Kola Peninsula is a region in which large industrial enterprises are located (the most significant here is the enterprise for the beneficiation and smelting of non-ferrous metals - the Severonikel plant). Studies to assess the negative impact of industrial pollutants on boreal communities in our country have been most actively carried out since the 70 s of the 20 th century $[7,8]$.

Purpose of the work: modern assessment of the state of the tree layer of pine forests exposed to airborne industrial emissions from the Severonikel plant.

\section{Materials and methods}

The object of research is lichen-green moss pine communities aged 60-80 years, located at different distances from the source of pollution with sulfur dioxide and polymetallic dust (impact and buffer zones) and varying degrees of disturbance.

The materials were obtained during the 2015, 2017 and 2018 field seasons at 4 permanent sample plots (PSP) oriented along the pollution gradient from the emission source to the background in the northern and southern directions: PSP $10 \mathrm{O}-10 \mathrm{~km}(\mathrm{~N} 68$ 00.384, E 03255.541 ), PSP 29 - $15 \mathrm{~km}$ (N 67 44.216, E 032 46.447), PSP $27 \mathrm{O}$ - $25 \mathrm{~km}$ (N 68 06.817, E 033 19.455), PSP 3 - $35 \mathrm{~km}$ (N 67 38.168, E 032 42.234). Two test plots were laid to the north of the pollution source, two to the south. This set of PSPs gives an idea of the plasticity of pine forest communities in this region as a result of anthropogenic impact (Fig. 4). 


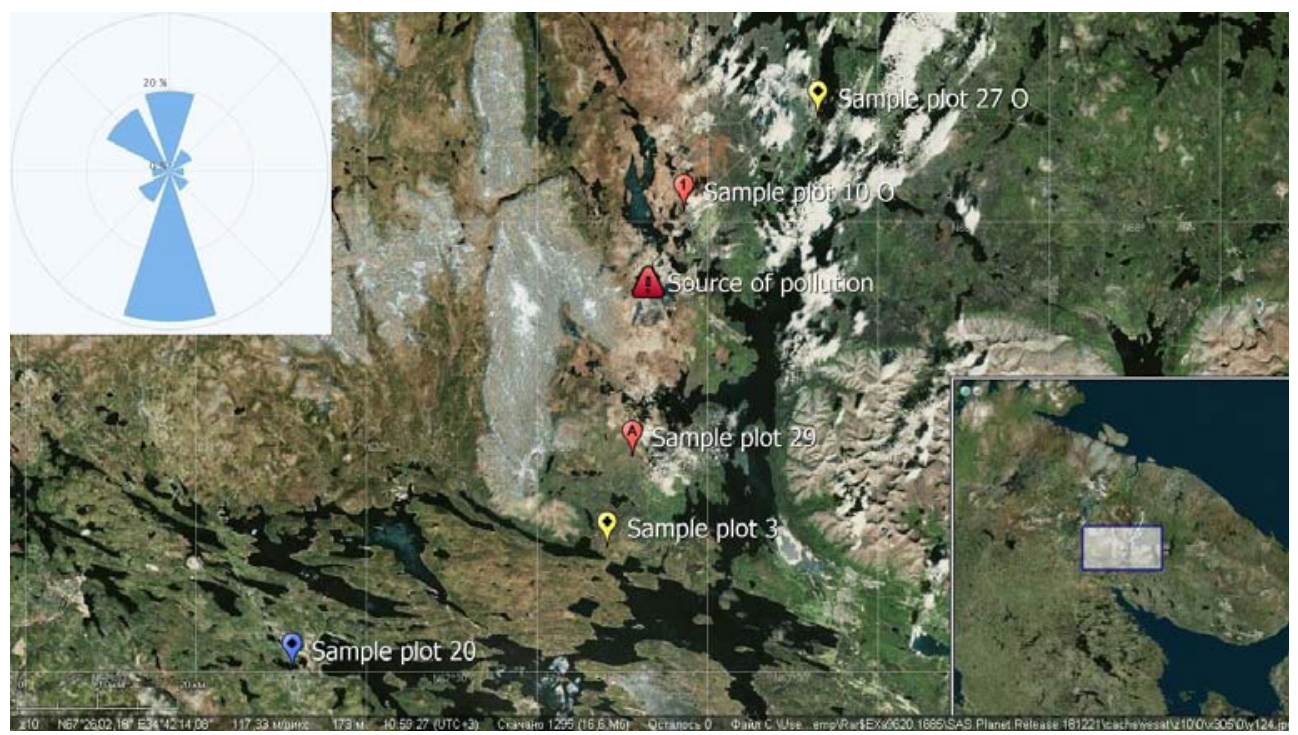

Fig. 4. Sample plots location map

On these permanent sample plots, the characteristics of the tree layer were obtained. We included all individuals of the forest-forming species with a trunk diameter of $4 \mathrm{~cm}$ or more at a height of $1.3 \mathrm{~m}$. Also, for all individuals of the stand, trunk diameter, tree height and vitality class were determined. We have identified 5 categories of life state: I - healthy individuals; II - defoliated individuals; III - severely defoliated individuals; IV - withered individuals; V - dead individuals). The vitality structure of the tree layer was analyzed. We also calculated the index of vitality class of the stand [9] by the formula:

$$
I_{n}=\frac{n_{1}+0.7 n_{2}+0.4 n_{3}+0.1 n_{4}}{n}
$$

Where: $I_{n}$ - vitality class index;

$n_{1}$ - the number of individuals classified as "healthy";

$n_{2}$ - the number of individuals classified as "defoliated";

$n_{3}$ - the number of individuals classified as "severely defoliated";

$n_{4}$ - the number of individuals classified as "withered";

$n-$ the total number of individuals.

\section{Results}

The study showed that the vitality structure and the index of the vital state of these communities of pine forests, which are in the zone of influence of airborne anthropogenic emissions from the enterprise, over a 3-year observation period is quite stable over this time interval.

The index of vitality class in 2015 for the impact zone was 0.56 and 0.49 (for PSP 100 and PPP 29, respectively). Distribution of trees by categories of vital status for PSP 10O: $15.7 \%$ healthy, $30.4 \%$ defoliated, $45.1 \%$ severely defoliated and $8.8 \%$ withered trees. For PSP 29, the same distribution was: $21.7 \%$ healthy, $20.7 \%$ defoliated, $24.8 \%$ severely defoliated and $32.8 \%$ withered trees. For the buffer zone, the index of vitality class was 0.83 and 0.79 (for PSP 270 and PSP 3, respectively). Distribution of trees by categories of vital status for PSP 27O: $70.8 \%$ healthy, $5.6 \%$ defoliated, $19.4 \%$ severely defoliated and 
$4.2 \%$ withered trees. For SPP 3, the same distribution was: $64.2 \%$ healthy, $12.6 \%$ defoliated, $10.6 \%$ strongly defoliated and $12.6 \%$ withered trees.

The index of vitality class in 2017 for the impact zone was 0.55 and 0.48 (for PSP 100 and PPP 29, respectively). Distribution of trees by categories of vital status for PSP 10O: $17.3 \%$ healthy, $30.2 \%$ defoliated, $39.7 \%$ severely defoliated and $5.5 \%$ withered trees. For PPP 29, the same distribution was: $25.8 \%$ healthy, $18.4 \%$ defoliated, $18.9 \%$ severely defoliated and $16.1 \%$ withered trees. For the buffer zone, the index of vitality class was 0.84 and 0.81 (for PSP 270 and PSP 3, respectively). Distribution of trees by categories of vital status for SPP 270: $72.0 \%$ healthy, $6.3 \%$ defoliated, $18.0 \%$ strongly defoliated and $1.5 \%$ withered trees. For SPP 3, the same distribution was: $66.9 \%$ healthy, $14.3 \%$ defoliated, $8.8 \%$ severely defoliated and $3 \%$ withered trees.

The index of vitality class in 2018 for the impact and buffer zones remained practically the same. For the impact zone, it was 0.56 and 0.48 (for PSP 100 and PSP 29, respectively), for the buffer zone - 0.84 and 0.82 (for PSP 27 O and PSP 3, respectively). The vital structure of these communities also did not undergo significant changes (Fig. 5).



Fig. 5. The index of vitality class of the tree layer at the PSP located at different distances from the pollution source.

\section{Conclusion}

As a result of the study, it is clearly seen that the vitality structure and the index of vitality class of pine forest communities in the studied region on these permanent sample plots in the period from 2015 to 2018 changed insignificantly, contrary to the general trend in the reduction of aerial anthropogenic emissions of polymetric dust and sulfur dioxide as a consequence, a decrease in the acid-soluble forms of $\mathrm{Cu}, \mathrm{Ni}$ and $\mathrm{Co}$ in the organic horizons of the soil and in the assimilation organs of plants. The main idea behind such seemingly contradictory data may be the fact that the tree layer at any level of impact (within the tolerance limit) will respond to environmental changes over a wider time range than other components of the community. It can also be associated with the prolonged accumulation of heavy metals in various soil horizons (both organic and mineral), which causes a very long-term restoration of pine forests in the impact and buffer zones. 


\section{References}

1. V. Gorshkov, I. Bakkal., N. Stavrova. Silva Fennica, 30(2-3), 209-219 (1996)

2. V. Yarmishko, V. Gorshkov, N. Stavrova. N. Plant resources, 39(4), 1-18 (2003)

3. V. Nikonov, V. Goryainova, N. Lukina. Chemosphere, 42(1), 93-100 (2001)

4. V. Nikonov, N. Lukina. Russian Journal of Ecology, 31(2), 82-89 (2002)

5. I. Lyanguzova. Russian Journal of Ecology, 48(4), 311-320 (2017)

6. A. Evdokimov. E3S Web of Conferences, 169, 01011 (2020)

7. V. Yarmishko. Scots pine and aerial pollution in the European North (Research Institute of Chemistry, St. Petersburg State University, 1997)

8. I. Lyanguzova, Heavy metals in ecosystems of northern taiga of Russia (LAP LAMBERT Academic publishing, 2016)

9. V. Yarmishko, I. Lyanguzova, Forest community research methods, 67-75 (Research Institute of Chemistry, St. Petersburg State University, 2002) 